\title{
(t)
}

\section{DESPOTISMO FINANCEIRO E POLÍTICAS AUSTERICIDAS: O ULTRALIBERALISMO EM AÇÃO}

\author{
Financial dispotismo and austericid policies: ultraliberalism in action
}

\author{
Carlos Roberto Marinho da Costa II* \\ htpps://orcid.org/0000.0003.0517.0589
}

\author{
Rosa Maria Cortês de Lima** \\ https://orcid.org/0000-0002-3670-8858
}

\section{RESUMO}

O presente artigo tem por objetivo discutir os determinantes contemporâneos da agenda de contrarreformas sociais brasileiras e a sua relação com a crise estrutural do capitalismo. A agenda neoliberal tem sido radicalizada no Brasil hodierno com a complexificação da austeridade fiscal imposta ao país e à América Latina pelos organismos multilaterais. Essa agenda guarda relação com as medidas liberalizantes que conformam o atual padrão de acumulação capitalista, em sua fase de financeirização, e transpassam a ação do Estado, por meio das políticas sociais e da articulação das contrarreformas sociais, que dão vazão à apropriação privada do fundo público. Os procedimentos metodológicos que compuseram a presente pesquisa incluem compilação e análise do banco de dados da PNAD-IBGE, em sua série histórica, além de pesquisa bibliográfica, a partir de artigos e livros que versam sobre o tema, com relevância no universo acadêmico-científico do Serviço Social.

\section{PALAVRAS-CHAVE}

Austeridade fiscal. Fundo público. Neoliberalismo. Estado e expropriações.

\footnotetext{
${ }^{*}$ Assistente Social. Mestre em Serviço Social. Doutorando em Serviço Social Universidade Federal de Pernambuco. Docente do curso de Serviço Social do Centro Universitário UNINASSAU e Secretário Municipal de Baarreiros-PE. R. Guilherme Pinto, 114 - Graças, Recife - PE, 52011-210.

E-mail: carlosrobertomar@hotmail.com.

** Assistente Social. Doutora em Planejamento Urbano e Regional. Professora Associado da Universidade Federal de Pernambuco. Professora do Programa de Pós-Graduação de Serviço Social - Departamento de Serviço Social Avenida dos Economistas s/n. Cidade Universitária. Recife, PE. CEP: 50 740-590. E-mail: cortez.rosa@gmail.com.
}

DOI 10.22422/temporalis.2021v21n41p84-101 material em qualquer suporte ou formato, bem como adaptar, transformar e criar a partir deste material para qualquer fim, mesmo que comercial. O licenciante não pode revogar estes direitos desde que você respeite os termos da licença. 


\title{
tomporalis
}

COSTA II, CARLOS ROBERTO MARINHO DA; LIMA, ROSA MARIA CORTÊS DE

\begin{abstract}
The purpose of this article is to discuss the contemporary determinants of the brazilian social counter-reform agenda and its relationship with the structural crisis of capitalism. The neoliberalism agenda has been radicalized in today's Brazil, with the complexification of the fiscal austerity agenda that has been imposed in Brazil and Latin America by multilateral organizations. This agenda is related to the liberalizing agendas that conform the current pattern of capitalist accumulation, in its phase of financialization and that permeate State action, through social policies and the articulation of a broad agenda of social counter-reforms, which give rise to appropriation of the public fund. The methodological procedures that made up this research include compilation and analysis of the PNAD-IBGE database, in its historical series, as well as bibliographical research, based on articles and books on the subject, relevant to the academic-scientific universe of the social work.
\end{abstract}

\section{KEYWORDS}

Fiscal austerity. Public fund. Neoliberalism. State and expropriations.

\section{INTRODUÇÃO}

Este artigo tem por objetivo discutir os determinantes contemporâneos da agenda de contrarreformas sociais brasileiras e sua relação com a crise estrutural do capitalismo, tendo por expressões imediatas o processo de expropriações dos direitos sociais, os movimentos regressivos de direitos representados pelas Emendas Constitucionais $n^{\circ} 93$ (BRASIL, 2016a), de 8 de setembro de 2016¹ (BRASIL, 2016), e $n^{\circ} 95^{2}$, de 15 de dezembro de 2016 (BRASIL, 2016b), além da movimentação recente do atual governo para minimizar a denominada crise fiscal do Estado brasileiro, presente no novo pacote de medidas (Propostas de Emendas Constitucionais nº 186 (BRASIL, 2019a), $n^{\circ} 187$ (BRASIL, 2019b) e $n^{\circ}$ 188 (BRASIL, 2019C)) que estão direcionadas para impor maior controle fiscal do fundo público, ao tempo em que estabelece relação com o ajuste fiscal liberalizante.

As recentes medidas adotadas pelo governo brasileiro se articulam com a agenda imposta pelos órgãos multilaterais na busca frenética pela viabilização de uma agenda ultraliberal voltada para aos interesses do capital. Isso não constitui uma atitude inédita, tampouco monolítica. Agrava-se em uma conjuntura marcada pelo questionamento do Estado enquanto mediador da proteção social, em favor da operacionalização do mercado como espaço de realização das necessidades sociais da população.

Essas medidas, conformadas enquanto ações de austeridade fiscal, inspiram-se em exame superficial e parcial das crises econômicas, que visam à criminalização do Estado, por uma suposta ineficiência, tributação excessiva, corrupção e mau uso do fundo público. Essa forma de abordagem das crises se converte em severa operação de inversão dos determinantes, como se as crises econômicas deixassem de guardar estreita relação com as formas de gestão do mercado, da mesma forma, com o desequilíbrio econômico da sociedade capitalista, estruturada em um sistema que tem como pedra angular a

\footnotetext{
${ }^{1}$ Altera o Ato das Disposições Constitucionais Transitórias para prorrogar a desvinculação de receitas da União e estabelecer a desvinculação de receitas dos Estados, Distrito Federal e Municípios .

${ }^{2}$ Altera o Ato das Disposições Constitucionais Transitórias, para instituir o Novo Regime Fiscal, e dá outras providências.
}

Temporalis, Brasília (DF), ano 21, n. 41, p. 303-319, jan./jun. 2021. | ISSN 2238-1856 


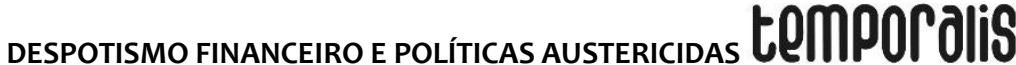

concentração vertiginosa de recursos, deixando de lado a partilha dos ganhos do trabalho coletivo.

Nesse lastro de discussão, busca-se analisar os fenômenos apresentados com o auxílio de duas categorias pertencentes ao universo teórico marxista: as expropriações contemporâneas e o fundo público. Nesta quadra histórica marcada, sobremaneira, pela centralidade do capitalismo financeiro e globalizado, que tem cunhado, nos termos de Dardot e Laval (2016), uma nova razão do mundo, sob o império do despotismo econômico muito peculiar às novas determinações neoliberais, elege-se como premente este debate, que é também elucidativo para a compreensão das novas determinações da relação entre Estado e mercado e dos impactos para o conjunto da classe trabalhadora.

O artigo, além desta introdução, está dividido em duas seções. A primeira seção intenta relacionar a agenda neoliberal e o dogma da austeridade fiscal ao atual modo de acumulação capitalista, mediante o desenvolvimento e consolidação do capitalismo financeiro, e a relação com a categoria expropriação, sendo a dívida pública o condutor desse processo, que trará como consequência última a necessidade da política de contrarreformas sociais. $\mathrm{Na}$ segunda seção, foram traçadas análises sobre a operacionalização da agenda de austeridade fiscal no Brasil e sua relação com o ideário ultraliberalizante e autoritário emergente na cena brasileira no ocaso dos governos petistas (2003-2016). Nesse item, abordamos as Emendas Constitucionais $n^{\circ}$ 93, de 8 de setembro de 2016, e $\mathrm{n}^{\circ}$ 95, de 15 de dezembro de 2016, que materializaram a agenda de expropriação de direitos, para o fomento da agenda austericida. Além disso, promovemos uma análise de Emendas Constitucionais que estão em debate nas casas legislativas, que aprofundam a austeridade fiscal e o desvio do fundo público das suas funções de proteção social para o caixa fiscal. Por fim, considera-se que a operacionalização da agenda austericida, conforme o dogma econômico liberal, guarda relações com o avanço do capitalismo financeiro e a pilhagem do fundo público pelas vias da ampliação da dívida pública, constituindo esta última uma fonte importante da valorização do capital, em tempos de capitalismo financeirizado. A dimensão da financeirização, conforme se desenha, sugere fortemente a agudização do distanciamento que envolve os países centrais dos países periféricos.

Este artigo foi elaborado em 2018, no calor dos eventos aqui apresentados, mas, como toda reflexão teórica, é herdeiro de seu tempo e raramente escapa às críticas corrosivas dos anos. São raras as produções que são capazes de preservar sua atualidade e conservar o vigor das ideias, a despeito da época em que foram escritas e das motivações que a conceberam. Entretanto, como a conjuntura histórica que aguçou a escrita do presente texto foi o prelúdio de uma série de eventos intencionais que desembocaram no adensamento de uma agenda ultraliberal e neofascista, soa adequado a revisitação de algumas chaves heurísticas abordadas ao longo do texto.

\section{REARTICULAÇÃO DA AGENDA NEOLIBERAL: SUPREMACIA DO CAPITALISMO FINANCEIRO E A DESCONSTRUÇÃO DA CIDADANIA SALARIAL}


A análise da sociedade sob a perspectiva da teoria marxista tem construído um denso conteúdo que busca compreender a natureza do modo de produção capitalista e a dinâmica societária operada desde sua eclosão. Um dos elementos consensuais nesse campo teórico é a compreensão da natureza expansiva do capitalismo devida à sua própria natureza de acumulação, materializada sob formas de exploração e dominação crescentes (LÊNIN, 2012; LUXEMBURGO, 1985).

Nessa trajetória de expansão das formas de exploração, o capitalismo se reinventa em função da lei geral de acumulação capitalista (MARX, 2014) como sua inspiração basilar. Mas, por outro lado, sua expansão se conforma como resoluções provisórias das contradições internas, conforme aponta Marx (2017a) na explicitação da lei da queda tendencial da taxa de lucro. Essa lei pretende evidenciar o movimento de expansão do capitalismo mediante a ampliação do capital constante em detrimento do capital variável, tendo-se como consequências desse movimento a ampliação da produtividade do trabalho de um lado e, de outro, a ampliação do exército industrial de reserva, como massa de trabalho humano qualificado e disponível para o trabalho.

O ocaso do chamado socialismo real, simbolicamente representado pela Queda do Muro de Berlim, em 1989, representou a dominação global do capitalismo, de modo que a expansão geográfica desse sistema foi saturada. Dessa forma, o capitalismo atingiu seu apogeu territorial preservando o processo de desenvolvimento desigual e combinado, conforme tratado por Trotsky (2007), um elemento fundante da dependência e do subdesenvolvimento brasileiro. No momento em que o sistema capitalista se globalizou, suprimindo o socialismo real, impulsionou o imperialismo e evidenciou a necessidade de novas formas de geração de valor, o que significou o aprofundamento do capitalismo financeiro, conforme já previsto por Marx (2017a). O capitalismo financeirizado será, portanto, um dos motores impulsionadores da agenda de austeridade fiscal, representando novas formas de expropriação, emergindo como novas estratégias de viabilização do capitalismo, enquanto projeto societário.

Para Trotsky (2007), quanto mais atrasado é um país, mais evoluída é a parte mais desenvolvida da sua economia. Defendia o autor que, quanto mais tarde um país se industrializasse, a burguesia local seria mais conservadora, já que o temor em relação ao proletariado seria muito maior que a sua oposição à aristocracia e às demais classes dominantes antecedentes. Assim, a burguesia optará por construir alianças com as classes dominantes para desenvolver o Estado burguês moderno e seu processo de industrialização, evitando romper com a estrutura de poder existente.

Os saltos de expansão capitalistas costumam se desenvolver em duas dimensões: (i) com o avanço na composição orgânica do capital (ampliação da base tecnológica e das formas de organização da produção; diversificação de produção e de mercantilização; expropriação dos direitos sociais, via mercantilização dos serviços sociais, e acesso a bens comuns da natureza, como água, fontes de energia, entre outras) e também (ii) com base na dominação ideológica, construída, nos termos de Dartot e Laval (2016), como uma sociomentalidade representativa de uma nova razão do mundo. Essa dimensão será explorada mais à frente, pois é nessa esfera que o ideário neoliberal irá operar nos processos que envolvem a reprodução capitalista. 
No primeiro movimento de expansão capitalista, referencia-se que a expropriação das políticas sociais, ou mesmo a expropriação do fundo público - como estratégia de expansão capitalista, ocorre na quadra histórica marcada pela ampliação do capitalismo financeiro, ou conforme expresso por Cohen (2017, p. 15): “O lucro capitalista já não é só apropriado pelos detentores de capitais, a partir da extração de mais valor ou de ganhos com o comércio desigual, mas é apropriado por uma punção do capital financeiro sobre o mais-valor extraído pelo capitalismo industrial e mercantil”.

Elaboram-se novas formas de exploração do trabalho que precisam ser intensificadas para nutrir a ânsia por lucros das frações do capital financeiro, mercantil e industrial, sem justa medida, uma vez que, no atual momento, o lucro global alcançado pelo capitalismo financeiro já ultrapassa o do capitalismo industrial (HARVEY, 2018). Um olhar desatento iria concluir que o capitalismo elaborou uma estranha alquimia: o alcance de uma forma de geração de lucros que não participa do circuito do trabalho, ou a conformação de "uma galinha dos ovos de ouro", como destacou lamamoto (2008). Nessa medida, a fórmula tecida por Marx, na busca de expressar a lei geral da acumulação capitalista D-M-D' teria evoluído para D-D', ou seja, dinheiro como gerador de mais dinheiro, sem a mediação do trabalho humano. Nesses termos, teria o capitalismo contemporâneo superado a teoria do valor-trabalho?

No livro III de O Capital, Marx concentrará esforços para a elucidação do dinheiro enquanto mercadoria, como o capital portador de juros, ou, nas palavras do velho alemão, os juros como "[...] a matriz de toda as formas insanas de capital [...]" (MARX, 2017a, p. 523). Entretanto, como o próprio Marx irá concluir, o juro se caracteriza enquanto mais-valia, do ponto de vista quantitativo, na tentativa de compreender o fluxo do dinheiro. Nessa perspectiva, pode-se atribuir o juro enquanto parte do lucro médio, que tem que ser paga pelo capitalista industrial, ou mercantil, ao capitalista monetário.

Destarte, o dinheiro toma forma de mercadoria, de modo que seu valor de troca se conforma como os próprios juros e seu valor de uso, pela disponibilidade de sua oferta para empréstimos (HARVEY, 2018). Assim, o próprio dinheiro, que é expressão/representação de valor, adquire um valor monetário, surgindo, com isso, o que Harvey (2018) denominou de "loucura da razão econômica", no momento em que a forma dinheiro se fetichiza, num pretenso movimento de multiplicação/valorização de seu valor de forma autônoma.

Entretanto, a conexão entre o avanço do capitalismo financeiro e as políticas de ajuste fiscal e pilhagem do orçamento público encontrará justificativa e razão de ser nos esforços estatais para manutenção da dívida pública, que, para Marx, é um agente enérgico da acumulação primitiva (MARX, 2017a). Assim sendo, torna-se possível inferir que a disciplina estatal contida nas medidas de austeridade fiscal e, em consequência, a minimização do Estado protetor representam uma renúncia ao exercício da responsabilidade com o cidadão, em favor da transferência de parcelas significativas do fundo público para o sistema financeiro. 


\section{tomporalis}

Há, conforme Boschetti e Teixeira (2019, p. 81), “[...] uma dialética interdependente entre expropriação de direitos e dívida pública [...]”, uma vez que a dívida pública tem seu lócus de operação no fundo público, que se avoluma na exata medida em que os governantes contraem empréstimos para honrar suas despesas. Consequentemente, pagam juros para amortização da dívida e do próprio capital da dívida, gerando o aumento de impostos, que dialeticamente obrigará a contratação de novos empréstimos, que em última medida representará a necessidade de ampliação de impostos sobre a classe que vive do trabalho e a redução dos direitos sociais.

É esse cenário, no qual haverá a soma de esforços no processo de acumulação por espoliação (HARVEY, 2014; BRAGA, 2017), que imporá uma série de agendas de contrarreformas sociais, incentivadas e fomentadas pelos órgãos multilaterais. Nesse sentido, a lógica do desenvolvimento das agendas de austeridade fiscal, impostas aos países periféricos, não traduz tão somente uma sistemática de poupar gastos, mas uma verdadeira agenda de espoliação de direitos, de modo a tratá-los como serviços, comercializáveis no mercado; ou dito de outra forma, converte-se valor de uso em valor de troca no mercado capitalista.

Nessa direção, as forças de mercado, tendo nos órgãos multilaterais um parceiro político fundamental, operam no sentido de marginalização do Estado enquanto mau administrador dos recursos públicos, sob uma compreensão ideologizada de redução das funções de proteção social do Estado e sua mutabilidade em formas de serviços disponíveis à população. Isso realiza o ideário norte-americano, conforme defendido por George W. Bush, do fim do "Estado Babá" e o reinado do império da liberdade e da meritocracia (HARVEY, 2016).

Como o diagnóstico operado pelos órgãos multilaterais é do desequilíbrio financeiro e do gasto excessivo do Estado e não enquanto uma crise econômica característica do modo de produção capitalista, que, portanto, denota um funcionamento ineficiente do mercado, a solução imposta é a redução do Estado social, conforme medidas de austeridade fiscal, ou, como denominamos, medidas austericidas. Essas medidas irão disputar a própria concepção dos papéis do Estado e dos direitos sociais na sociedade capitalista madura, bem como o status do trabalho assalariado e as formas de assalariamento, de acordo com a análise de Harvey (2016), expressa a seguir.

Em termos gerais, o mundo está polarizado entre a continuação ou até o aprofundamento das soluções neoliberais, baseadas na oferta (suplly-side) e monetaristas, enfatizando a austeridade como remédio apropriado para curar nossos males (caso da Europa e dos Estados Unidos), e a retomada de uma visão em geral diluída de uma expansão keynesiana baseada na demanda e financiada com a dívida (como na China) ignorando a ênfase de Keynes na redistribuição de renda para as classes mais baixas como um de seus componentes-chave. Não importa qual política é seguida: o resultado é o favorecimento do clube de bilionários que hoje constitui uma plutocracia cada vez mais poderosa no cenário mundial (HARVEY, 2016, p. 10).

Essa operação se consolida ou recebe o contributo singular da revanche liberal, ou seja, com a repaginação do dogma liberal de livre mercado e da minimização da figura do Estado, com a fusão entre mercado e Estado, de modo que o Estado passa a se configurar

Temporalis, Brasília (DF), ano 21, n. 41, p. 303-319, jan./jun. 2021. | ISSN 2238-1856 
como o principal prestamista do capital (IAMAMOTO, 2008). Esse prestamismo estatal se consolida por meio da normatização dos dogmas liberais ${ }^{3}$, que trata de disputar idelogicamente a orientação social do Estado. Essa orientação é imposta pelas vias legais e pela liberalização da sociedade, que passam a integrar as leis e condutas morais ${ }^{4}$, pelo financiamento direto e indireto do desenvolvimento capitalista, tendo como fonte financeira privilegiada o fundo público. O austerismo estatal toma forma de expropriação quando o Estado minimiza as políticas de proteção social estatal em função da viabilização do desenvolvimento econômico-financeiro.

Como forma de liberalização da sociedade, por meio do controle ideológico, ou, nos termos de Dardot e Laval (2016), como sociomentalidade, a razão do mundo liberal irá operar novas significações para o sujeito neoliberal, de modo que o status de cidadania salarial é alterado para a lógica do indivíduo empreendedor, sendo descaracterizada por completo a regulamentação do trabalho formal, sob alegações da exploração das capacidades humanas. O objetivo final é que os indivíduos sejam apartados dos mecanismos públicos de proteção social e possam operar individualmente enquanto sujeitos S/A. Em outras palavras, o objetivo é que os indivíduos desenvolvam valores político-econômicos liberais a ponto de operarem como empresas, gerenciando seus próprios riscos pessoais e sociais.

Sob esse prisma, reforçam-se os valores meritocráticos, próprios da sociedade liberal, e se estabelece um novo espírito do capitalismo, que motivará o engajamento social dos indivíduos no sistema pelas vias do empreendedorismo, como substitutivo do trabalho formal, que redimensionará a superpopulação relativa nas diversas formas de existência. Noutra dimensão, o crescimento da pauperização, nos marcos da decadência da proteção social estatal e da primazia da economia sobre a política e o Estado, adensará a barbárie capitalista em direção aos processos de supercapitalização, para usar os termos de Mandel (1982), ou, de forma análoga, em termos do superexcedente (OLIVEIRA, 2013). Desse modo, a engenharia da acumulação capitalista comportará o avanço da exploração do capital em funções anteriormente consolidadas e reconhecidas como funções do Estado protetor, com destaque para as políticas de seguridade social, expondo os indivíduos à sua própria sorte.

\section{AS CONTRARREFORMAS BRASILEIRAS, POLÍTICAS AUSTERICIDAS E O AVANÇO DO CAPITALISMO-BÁBARIE}

A trajetória recente do Brasil registra uma grande evolução em direção aos avanços nos direitos sociais, tendo como marco histórico a transição à redemocratização e à

\footnotetext{
${ }^{3}$ Aqui destacamos o papel fundamental do Ordoliberalismo alemão, que defendia a relação entre Estado e mercado, no âmbito da ordem legal, ou seja, a liberalização da economia e o mercado "livre" não poderiam se conformar enquanto pautas dos liberais, mas enquanto condutas do Estado, construindo novos elementos de consenso e de hegemonia (DARDOT; LAVAL, 2016).

${ }^{4}$ Desde a origem no capitalismo, enquanto sistema de produção, o Estado media os privilégios da classe burguesa, muitas vezes expropriando direitos, na maioria das vezes consolidados. São exemplos históricos a Lei do Cercamento dos Campos, a Lei do Furto da Madeira (MARX, 2017b), dentre outras. Assim, as leis e normativas, sob império de um Estado burguês e neoliberal, têm componentes ideológicos estruturantes para as formas de exploração e dominação.
} 
promulgação da Constituição Federal de 1988. Entretanto, o cenário político-econômico e social exposto no item anterior nos conduz à conclusão de que a Constituição Cidadã guarda uma relação anacrônica com o movimento do capitalismo recente, de modo que, se em uma direção as forças sociais progressistas da nação requeriam o avanço da proteção social estatal e, portanto, a aproximação ao modelo de bem-estar social europeu, em outra direção as forças conservadoras alinhadas ao capitalismo globalizado impunham uma dura política estatal de contrarreformas, com forte tendência à austeridade fiscal e disputa pelo fundo público (BEHRING, 2018).

Sob o auspício da superacumulação propiciada pelo avanço do capitalismo financeiro, que gerou o nascimento de uma elite de bilionários ${ }^{5}$, tendo sob seu comando uma grande soma de capitais que necessita, pela própria natureza do capitalismo, de valorização, o capital almeja encontrar novas formas para sua multiplicação, como a exploração de serviços sociais e de fornecimento de água, ou do uso de ar e fontes de energia não renováveis, como o petróleo, entre outras alternativas (MOTA, 2018; BRAGA, 2017). Dessa forma, o capital sobreacumulado cobiça a apropriação desses ativos, promovendo o que Harvey (2014) denominou de "acumulação por espoliação", sendo esta uma tendência do novo imperialismo.

Assim, parece haver um consenso entre Harvey (2014) e Braga (2017) de que há, no capitalismo contemporâneo, uma unidade entre exploração e espoliação nas formas de reprodução e expansão capitalista, com fortes impactos na figura do Estado protetor e nas formas de trabalho. Braz (2012) sintetiza a macrotendência desse processo em três aspectos:

1) capitalização de setores ainda pouco explorados pelo mercado capitalista, transformando a oferta de serviços públicos e estatais - saúde, educação, previdência, saneamento etc. - em negócio; 2) exploração mercantil e industrial de recursos naturais dos países periféricos; 3 ) investimento nos setores rentistas, preferencialmente nos setores de renda fixa que melhor remuneram o capital, como títulos da dívida pública de países como o Brasil, relacionando-se diretamente com a questão dos juros e amortizações da dívida pública (BRAZ, 2012, p. 475).

Retomando a reflexão da categoria espoliação à realidade brasileira, compreende-se que a transição do Estado ditatorial-militar brasileiro à redemocratização não foi suficiente para superação da realidade periférica e dependente em relação ao capitalismo central, sendo utilizada como intermédio para realização das agendas neoliberais já sinalizadas no capítulo anterior. Mesmo no período petista (2003-2016), apontado por alguns estudiosos 6

\footnotetext{
${ }^{5}$ Conforme Daniel Bensaid: "[...] no fim de 2003, a capitalização mundial das bolsas de valores chegou a 31 trilhões de dólares, ou seja, quase $90 \%$ do produto interno bruto do mundo". Os acionistas possuem mais de três quartos do patrimônio comercial da humanidade [...] de maneira que $5 \%$ da população mundial detém quase a totalidade dos bens em bolsa do mundo e 77 mil famílias 'ultrarricas' detêm sozinhas 15\% da riqueza mundial (BENSAID, 2017, p. 17).

${ }^{6}$ A produção da área de Ciências Sociais e do Serviço Social tomou o neodesenvolvimentismo como um ponto de reflexão polêmico. Enquanto alguns autores, como Singer (2012), constroem a tese do lulo-petismo como um reformismo fraco, outros, como Mota (2018), argumentam em favor da manutenção da agenda liberal e da continuidade da sociabilidade capitalista, pois não há formas de superação das desigualdades capitalistas sem a superação da ordem imposta por esse sistema de produção.
}

Temporalis, Brasília (DF), ano 21, n. 41, p. 303-319, jan./jun. 2021. | ISSN 2238-1856 
como uma quadra histórica de reavivamento do desenvolvimentismo, ou neodesenvolvimentismo, em alusão ao nacional-desenvolvimentismo, o Estado brasileiro não se apartou das determinações do ideário neoliberal e das políticas macroeconômicas "aconselhadas" pelos órgãos multilaterais.

Desse modo, na era lulista conservou-se uma estreita relação com as políticas sociais distributivas, a exemplo dos programas de transferência de renda, tendo representado ganhos para a classe trabalhadora, mas cumprindo o papel contraditório de ampliação do comprometimento do fundo público com o sistema financeiro. Nessa direção, a União preservou como prioridade orçamentária o gasto com a dívida pública, dando sinais de que os credores da dívida pública podiam se favorecer do prestamismo do Estado brasileiro.

A esse respeito, Behring (2018) apresenta um compilado de dados orçamentários que revela o comprometimento dos governos lulistas com o capitalismo portador de juros. Diz a autora que: "[...] em 2011 o governo cortou R\$ 50 bilhões do orçamento; em 2012, efetuou o contingenciamento de R\$5 55 bilhões [...]; em 2014, de 44 bilhões de reais" (BEHRING, 2018, p. 59). Desse modo, a economia brasileira teve no contingenciamento orçamentário um grande aliado para a manutenção do superávit primário, seguindo, assim, o acordo celebrado com o FMI, em 1999, de preservação da segurança dos credores da dívida pública.

Esse esforço para a implementação de um projeto de governo neodesenvolvimentista, que teria gerado uma nova classe média, sem a ruptura com os parâmetros neoliberais, conduziu a muitas reflexões que sinalizavam para as inconsistências das propostas lulopetistas. Na compreensão de Arcary (2011), desenvolveu-se no Brasil um período de reformismo sem reformas, enquanto para Singer (2012) esta proposta se conformou como um reformismo fraco. O espectro dessa leitura dos governos petistas concentra esforços na compreensão de que houve uma queda nas desigualdades sociais brasileiras, mas, sendo uma redução pífia, de modo que a iniquidade não foi alterada.

Quando examinamos diretamente os dados, verificamos um avanço considerável de determinados indicadores sociais (redução da extrema pobreza, reajuste real do salário mínimo, acesso à educação, entre outros ${ }^{7}$ ). Para tomar como prisma de análise os dados disponíveis sobre desigualdade de renda, verifica-se uma variação entre os cenários, conforme ilustra o Quadro 1, a seguir, que sinaliza leve redução progressiva da concentração de renda dos mais ricos e a oscilação da renda dos mais pobres no período entre os anos 2000 e 2018.

Quadro 1: Rendas dos Mais Ricos e Mais Pobres

\begin{tabular}{|l|l|l|}
\hline ANO & Renda dos 10\% mais ricos & Renda dos $10 \%$ mais pobres \\
\hline 2000 & $47 \%$ & $0,5 \%$ \\
\hline 2010 & $45 \%$ & $1 \%$ \\
\hline 2018 & $43,1 \%$ & $0,8 \%$ \\
\hline
\end{tabular}

Fonte: Instituto Brasileiro de Geografia e Estatística (2019).

7 Ver Singer (2012).

Temporalis, Brasília (DF), ano 21, n. 41, p. 303-319, jan./jun. 2021. | ISSN 2238-1856 
Quando comparamos esses dados com a série histórica da PNAD contínua (anos de 2000, 2010 e 2018) em relação ao índice de GINI, percebemos que há tendência à estagnação da queda da desigualdade social no país. Esse indicador era de 0,588, em 2002, e de 0,501, em 2011. Em 2017, o mesmo indicador passou por relativo crescimento, de acordo com a mesma fonte, chegando a 0,549; e, em 2018, atingiu 0,545. Isso revela que o crescimento econômico ocorrido ao longo dos governos Lula (2003-2010) não foi eficaz para alterar o caráter de país subdesenvolvido e dependente das economias centrais. Isso fica ainda mais patente quando examinamos os postos de trabalho gerados no Brasil. Segundo Pochmann (2012), 95\% das vagas abertas entre os anos 2000 a 2010 tinham remuneração de até 1,5 salário mínimo.

Mesmo reconhecendo muitos dos avanços sociais alcançados no período dos governos do Partido do Trabalhadores, desde 2003, vale assinalar que esse bloco histórico heterogêneo não conseguiu conter as tendências estruturais do contexto de mundialização financeira, sob o auspício da espoliação enquanto estratégia de acumulação. Mas é com o golpe de Estado jurídico-parlamentar articulado em 2016, no Brasil, que o país caminha de forma acelerada em direção à maior flexibilização do fundo público, enquanto acumulação primitiva de capital, impondo à classe trabalhadora o "direito" à miséria. Esse golpe expressou um complexo amálgama que envolve a fusão de ajustes espaço-temporais (HARVEY, 2016) com a supercapitalização (MANDEL, 1982). Partindo-se da premissa de que a economia capitalista entrou em uma crise profunda (MÉSZÁROS, 2008, HARVEY, 2016) na década de 1970, e que, portanto, o motor capitalista está em pleno declínio, há dilemas na absorção do excedente de capital e trabalho, de modo que transparece a necessidade de que uma parte do capital se ajuste a determinado lugar, por um período relativamente longo.

Desse modo, o conceito de ajustes espaço-temporais explica, em complementaridade com a concepção trotskista de capitalismo desigual e combinado, o atual papel que o Brasil tende a desenvolver no capitalismo globalizado, alinhado a outras economias latinoamericanas, a exemplo do Chile, Equador e Colômbia, entre outras. Na mesma quadra histórica em que as economias centrais adentram no que foi convencionado de indústria 4.0, ou $4^{a}$ Revolução Industrial, os países da América do Sul, de modo muito particular o Brasil, caminham em direção à desindustrialização e ao fortalecimento da economia concentrada na produção de commodities, mais suscetível, por conseguinte, às crises econômicas. Em relação à afinidade do cenário político-econômico brasileiro contemporâneo com as reflexões de Mandel sobre a supercapitalização, vale ressaltar a natureza do próprio termo, nas palavras de Behring (2015).

As dificuldades recentes de valorização do capital alavancam a penetração deste em investimento que não produz necessariamente mais-valia em algumas circunstâncias. A supercapitalização, processo no qual uma forte liquidez de capital se faz acompanhar de sua penetração e/ou busca de nichos de valorização, é o fundamento dos processos atuais de "invenção" de novas necessidades, industrialização das esferas do lazer, da cultura e até da seguridade social, bem como de processos de privatização de setores produtivos antes assumidos pelo Estado (BEHRING, 2015, p. 141). 
Assim, torna-se possível afirmar que estamos vivendo um novo momento neoliberal no Brasil, tensionado pelos desdobramentos da última grande crise do capitalismo, que se agudizou em 2008/2009, alavancada pela quebra da cadeia de créditos subprime e pelo estouro da bolha imobiliária americana. Nessa direção caminha o documento Uma Ponte Para o Futuro, elaborado pelo Partido PMDB, que conduziu muitas lideranças dos partidos identificados como Centrão ${ }^{8}$ a operarem o Golpe de 2016, retomando a agenda mais dura do Consenso de Washington, que aponta para o aprofundamento das políticas de austeridade fiscal. Isso implica em privatizar tudo o que for passível de mercantilização, portanto, implica a transmutação de direito em serviço, além do adensamento do Estado empresarial-neoliberal, materializando os preceitos do ordoliberalismo.

$\mathrm{Na}$ direção da supercapitalização, o governo Michel Temer (2016-2018) desenvolveu medidas de austeridade fiscal e de redução do orçamento social do governo brasileiro, tendo como modus operandi a aprovação de emendas constitucionais regressivas de direitos, como a EC n 93/2016, que amplia os efeitos da Desvinculação de Receitas da União (DRU), ampliando seu percentual de desvinculação de $20 \%$ para 30\% , além da EC n 95/2016, que estabelece novo regime fiscal, com o congelamento dos gastos públicos por 20 anos. As duas emendas representaram o ápice da disputa pelo fundo público, numa verdadeira cruzada por ampliação da participação do orçamento público nas dotações e rubricas afetas ao desenvolvimento econômico. Em última medida, as emendas constitucionais supracitadas, com o auxílio da última reforma trabalhista brasileira, mediam a ampliação da espoliação à classe trabalhadora brasileira, em tempos de neoliberalismo ultraortodoxo ${ }^{10}$.

A estratégia de formulação de um novo regime fiscal para o Brasil, com congelamento dos gastos públicos por 20 anos, é medida inédita no mundo. Segundo Carvalho (2016), 22 países adotam medidas de controle de gasto público, mas em nenhum deles a regra é longeva a tal ponto, até mesmo porque podem surgir situações de contingências, que exijam a atuação emergencial do Estado, a exemplo de tragédias e calamidades públicas.

$\mathrm{Na}$ quadra histórica representada pela ascensão de Jair Messias Bolsonaro ao cargo máximo da nação em 2019, opera-se uma verdadeira cruzada acelerada contra o incipiente Estado Social brasileiro e o desenvolvimento de um ultraliberalismo, azeitado por elementos de reacionarismo mesclados com conteúdos autoritários. A agenda econômicosocial encampada pelo ministro da economia deste governo, Paulo Guedes, e os

\footnotetext{
8 O Centrão é constituído por um bloco de deputados formado pelos seguintes partidos: Partido Trabalhista Brasileiro (PTB), Partido Progressista (PP), Partido Social Democrático (PSD), Movimento Democrático Brasileiro (MDB) e Democratas (DEM).

9 Em 2018, a Desvinculação de Receita da União (DRU) da seguridade social atingiu R\$ 109,6 bilhões. A desvinculação é crescente ao longo do tempo, em função do próprio comportamento da arrecadação, mas teve avanço mais significativo de 2015 para 2016, quando houve a alteração do percentual desvinculado de $20 \%$ para $30 \%$. A previsão de desvinculação para 2019 foi de $R \$ 123,8$ bilhões, segundo a Secretaria do Tesouro Nacional (STN).

${ }^{10}$ Analisando comparativamente a Lei de Diretrizes Orçamentárias de 2018 e o projeto de diretrizes orçamentárias de 2019, chama a atenção o crescimento da meta do superávit primário, que passou de R\$ $1.2000 .000,00$ (um bilhão e duzentos milhões de reais) para $\mathrm{R} \$ 10.500 .000,00$ (dez bilhões e quinhentos milhões de reais), representando um crescimento de $875 \%$.
}

Temporalis, Brasília (DF), ano 21, n. 41, p. 303-319, jan./jun. 2021. | ISSN 2238-1856 
denominados Chicago boys ${ }^{11}$ se expressa em medidas amargas para a classe trabalhadora. Entre os espectros dessas ações, encontram-se um ajuste fiscal draconiano e o controle do fundo público pelo capital portador de juros, que terá, como última consequência, a redução drástica do acesso às políticas sociais. Desse modo, podemos inferir que há, no governo atual, a tendência do reinado do despotismo financeiro e do fim da cidadania salarial, com medidas amargas para a classe trabalhadora como a intensificação da reforma trabalhista, a ampliação da contrarreforma social e a proposta de desvinculação total das receitas da União. Enfim, a desestruturação dos sistemas de proteção social com a pilhagem do fundo público.

Como expressão do avanço das medidas austericidas, no final do ano de 2019, foi apresentado no Senado brasileiro um pacote de emendas constitucionais com vistas à contenção e amenização da crise fiscal, com medidas que põem em xeque a capacidade do Estado brasileiro de financiar o Estado Social. Trata-se das Propostas de Emendas Constitucionais $n^{\circ} 186, n^{\circ} 187$ e $n^{\circ} 188$, cujos conteúdos e aprovações ainda serão debatidos nas casas legislativas, mas que expressam medidas de controle e ajuste fiscais, com modificações estruturais no orçamento público e na forma de destinação de impostos e gestão dos fundos públicos, o que repercutirá nas formas e modalidades de atendimento das políticas sociais.

\section{CONSIDERAÇÕES FINAIS}

Na realidade brasileira, a tessitura de uma agenda ultraliberal, e suas consequências, se impôs por meio de uma vasta agenda de questionamento do Estado, enquanto mediador dos processos sociais, num repertório comum de corrupção estatal generalizada, que ocasionou o impeachment da Presidenta Dilma Rousseff ${ }^{12}$ e o processo de consolidação das novas agendas liberais capitalistas, em sintonia com os interesses dos multimilionários que farejam espaços globais para a realização da valorização do capital superacumulado. No Brasil, está em construção o Sísifo tupiniquim, sob o signo da barbárie. Enquanto o Sísifo, personagem da mitologia grega, executava trabalhos rotineiros cansativos, como castigo para demonstrar que os mortais não tinham a mesma liberdade dos deuses, tornando-se cativos na repetição e na monotonia, nestas terras, projeta-se a intensificação do trabalho abstrato virtual, que, mesclado a uma proteção social impiedosa e impenitente, articula a necropolítica que visa à desconstrução da cidadania salarial e à viabilização do direito à miséria e ao privilégio da servidão.

Nesse cenário, opera-se o distanciamento entre os países centrais e periféricos, acentuando a condição de subdesenvolvimento brasileiro e extinguindo a utopia de uma terceira via na cadeia da economia capitalista globalizada, que desenhava a articulação de um polo de países em desenvolvimento, do qual o Brasil faria parte. Acentua-se, outrossim,

\footnotetext{
${ }^{11}$ Termo usado em alusão ao grupo de economistas que conduziram as contrarreformas chilenas durante o regime de Augusto José Ramón Pinochet Ugarte (1973-1990), que inspiram, em certa medida, as propostas do atual ministro da economia, Paulo Guedes. Esses economistas foram pós-graduados pela Universidade de Chicago, escola tradicionalmente liberal.

${ }^{12}$ Seu segundo mandato (2015-2018) foi interrompido em 31 de agosto de 2016, em virtude de um processo de impeachment, aberto pelo Poder Legislativo, que neste artigo é denominado de Golpe de novo tipo, pois traz em seu bojo diversas incongruências.
}

Temporalis, Brasília (DF), ano 21, n. 41, p. 303-319, jan./jun. 2021. | ISSN 2238-1856 
a histórica condição de desemprego estrutural dos países periféricos, por meio da intensificação da desregulação e da consequente precarização do trabalho, o que é funcional para a dinâmica da economia dependente. Como forma de agudização da subsunção do labor às formas precárias de trabalho, opera-se, ainda, a supressão/expropriação de políticas, benefícios e formas de proteção social, que impactam diretamente na condição de vida das classes trabalhadoras. Além disso, transformam-se serviços em mercadorias, mediadas pelo capital portador de juros, fazendo emergir uma nova figura no âmbito da contrarreforma social do Estado, que Mota (2018) denominou de "trabalhador-consumidor-expropriado".

As mudanças abordadas neste artigo, como processo de expropriação/espoliação, são estratégias impostas no mundo do trabalho, mediante as reformas trabalhistas, no financiamento da incipiente proteção social brasileira, com a implementação das $E C n^{\circ} 93$ e $\mathrm{n}^{\circ}$ 95, ou mesmo com o mais novo pacote de medidas provisórias apresentado no Senado, conforme já mencionamos. Essas alterações têm como único beneficiário inconteste os credores da dívida pública. Isso se torna evidente quando verificamos que o primeiro item do gasto público é o pagamento dos juros da dívida, que consumiu em 2020 em média 39,08\% do orçamento público brasileiro, segundo a auditoria cidadã da dívida.

No contexto de agravamento da crise do capital, as políticas sociais passam a ser alvos fáceis para mercantilização, desfinanciamento, contingenciamento ou mesmo extinção, como estratégia para preservar o aquecimento do mercado ou para manter o bom humor da economia. Dessa forma, na defesa do deus-mercado, corroem-se o sistema de proteção social brasileiro e o seu financiamento. Isso se expressa no mosaico muito amplo de expropriações dos direitos sociais em favor da exploração da força de trabalho e da acumulação capitalista, particularmente em sua versão financeirizada. Assim, convive-se não apenas com mais um momento de expropriações, mas com a radicalização da transmutação do fundo público enquanto acumulação primitiva de capital, ou, conforme Fernandes (1975), com mecanismos contínuos de "[...] sobreacumulação e sobreapropriação [...]" (FERNANDES, 1975, p. 45) das disputas em torno dos usos do fundo público.

Deve-se ponderar, entretanto, que essa perspectiva não se reserva ao fatalismo, mas é uma leitura necessária, dada a conjuntura da sociedade brasileira atual. Conforme pontua Marx (2011): "Os homens fazem sua própria história; contudo não a fazem de livre e espontânea vontade, pois não são eles quem escolhem as circunstâncias sob as quais é feita, mas estas foram transmitidas assim como se encontram" (MARX, 2011, p. 25). Então, a história também pode ser testemunha da revanche dos trabalhadores sobre o capital, uma vez que é sob a intensa ofensividade das classes dominantes sobre os subalternos que a rebeldia pode surgir, senão como expressão da organização dos trabalhadores e de sua identidade de classe, ao menos sob o instinto da sobrevivência.

\section{REFERÊNCIAS}

ARCARY, Valério. Um reformismo quase sem reformas: uma crítica marxista do governo Lula em defesa da revolução brasileira. São Paulo: Sundermam, 2011. 
BEHRING, Elaine Rosseti. Estado no capitalismo: Notas para uma leitura crítica do Brasil recente. In: BOSCHETTI, Ivanete. Expropriações e direitos no capitalismo. São Paulo: Cortez, 2018. p. 198- 210.

BEHRING, Elaine Rosseti. Política social no capitalismo tardio. São Paulo: Cortez, 2015.

BENSAID, Daniel. Prefacio. In: MARX, Karl. Os despossuídos. São Paulo: Boitempo, 2017.

BOSCHETTI, Ivanete; TEIXEIRA, Sandra Oliveira. O draconiano ajuste fiscal no Brasil e a expropriação de direitos da seguridade social. In: BEHRING, Elaine; LIMA, Rita de Lourdes de; SALVADOR, Evilásio. Crise do capital e fundo público: implicações para o trabalho, os direitos e a política social. São Paulo: Cortez, 2019. p. 76-98.

BRAGA, Ruy. A rebeldia do precariado: trabalho e neoliberalismo no sul global. São Paulo: Boitempo, 2017.

BRASIL. Proposta de Emenda Constitucional $\mathbf{N}^{\circ} \mathbf{1 8 6}$, de 2019. Altera o texto permanente da Constituição e o Ato das Disposições Constitucionais Transitórias, dispondo sobre medidas permanentes e emergenciais de controle do crescimento das despesas obrigatórias e de reequilíbrio fiscal no âmbito dos Orçamentos Fiscal e da Seguridade Social da União, e dá outras providências. Brasília (DF), 2019a. Disponível em: https://www25.senado.leg.br/web/atividade/materias/-/materia/139702. Acesso em: 10 mar. 2020.

BRASIL. Proposta de Emenda Constitucional $N^{\circ}$ 187, de 2019. Institui reserva de lei complementar para criar fundos públicos e extingue aqueles que não forem ratificados até o final do segundo exercício financeiro subsequente à promulgação desta Emenda Constitucional, e dá outras providências. Brasília (DF), 2016b.Disponível em: https://www25.senado.leg.br/web/atividade/materias/-/materia/139703. Acesso em: 10 mar. 2020.

BRASIL. Proposta de Emenda Constitucional $N^{\circ} 188$, de 2019. Altera arts. $6^{\circ}, 18,20,29-A$, 37, 39, 48, 62, 68, 71, 74, 84, 163, 165, 166, 167, 168, 169, 184, 198, 208, 212, 213 e 239 da Constituição Federal e os arts. 35, 107,109 e 111do Ato das Disposições Constitucionais Transitórias; acrescenta à Constituição Federal os arts. 135-A, 163-A, 164-A, 167-A, 167-B, 168-A e 245-A; acrescenta ao Ato das Disposições Constitucionais Transitórias os arts. 91A, 115, 116 e 117; revoga dispositivos constitucionais e legais e dá outras providências. Brasília (DF), 2016c. Disponível em: https://www25.senado.leg.br/web/atividade/materias//materia/139704. Acesso em: 10 mar. 2020.

BRASIL. Emenda Constitucional № 93, de 8 de setembro de 2016. Altera o Ato das Disposições Constitucionais Transitórias para prorrogar a desvinculação de receitas da União e estabelecer a desvinculação de receitas dos Estados, Distrito Federal e Municípios. Brasília (DF), 2016a. Disponível em:

http://www.planalto.gov.br/ccivil_03/constituicao/Emendas/Emc/emc93.htm. Acesso em: 10 mar. 2020. 


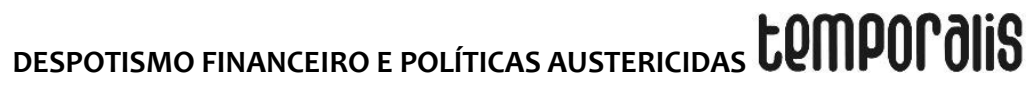

BRASIL. Emenda Constitucional N 95, de 15 de dezembro de 2016. Altera o Ato das Disposições Constitucionais Transitórias, para instituir o Novo Regime Fiscal, e dá outras providências. Brasília (DF), 2016b. Disponível em:

http://www.planalto.gov.br/ccivil_03/constituicao/emendas/emc/emc95.htm. Acesso em: 10 mar. 2020.

BRAZ, Marcelo. Capitalismo, crise e lutas de classes contemporâneas: questões e polêmicas. Revista Serv. Soc. Soc. [online]. 2012, n.111, pp.468-492. Disponível em: SciELO - Brasil - Capitalismo, crise e lutas de classes contemporâneas: questões e polêmicas Capitalismo, crise e lutas de classes contemporâneas: questões e polêmicas. Acesso: 3 ago. 2015.

CARVALHO, Laura. 10 perguntas e respostas sobre a PEC 241 (EC 95). Blog da Boitempo, São Paulo, 2016. Disponível em: https://blogdaboitempo.com.br/2016/10/13/10-perguntase-respostas-sobre-a-pec-241/. Acesso em: 10 mar. 2020.

COHEN, Michel. Prefacio. In: BRAGA, Ruy. A rebeldia do precariado: trabalho e neoliberalismo no sul global. São Paulo: Boitempo, 2017.

DARDOT, Pierre; LAVAL, Christian. A nova razão do mundo: Ensaio sobre a sociedade neoliberal. São Paulo: Boitempo, 2016.

FERNANDES, Florestan. Capitalismo dependente e classes sociais na América Latina. Rio de Janeiro: Zahar, 1975.

HARVEY, David. A loucura da razão econômica: Marx e o capital do século XXI. São Paulo: Boitempo, 2018.

HARVEY, David. 17 contradições e o fim do capitalismo. São Paulo: Boitempo, 2016.

HARVEY, David. O novo imperialismo. São Paulo: Loyola, 2014.

IAMAMOTO, Marilda Vilela. Serviço Social em tempos de capital fetiche: capital financeiro, trabalho e questão social. São Paulo: Cortez, 2008.

INSTITUTO BRASILEIRO DE GEOGRAFIA E ESTATÍSTICA (IBGE). Pesquisa Nacional por Amostra de Domicílios (PNAD). Brasília (DF), 2019. Disponível em: https://www.ibge.gov.br/estatisticas/sociais/populacao/9171-pesquisa-nacional-poramostra-de-domicilios-continua-mensal.html?=\&t=0-que-e. Acesso em: 30 abr. 2020, as 9h:32min.

LÊNIN, Vladimir llyich. Imperialismo, estágio superior do capitalismo. São Paulo: Expressão Popular, 2012.

LUXEMBURGO, Rosa. Acumulação de capital: contribuição ao estudo econômico do imperialismo. São Paulo: Nova Cultural, 1985. 
MANDEL, Ernest. O capitalismo tardio. 2. ed. São Paulo: Nova Cultural, 1982.

MARX, Karl. O Capital. São Paulo: Boitempo, 2017a. (Livro III).

MARX, Karl. Os despossuídos. São Paulo: Boitempo, $2017 \mathrm{~b}$.

MARX, Karl. O Capital. São Paulo: Boitempo, 2014. (Livro I).

MARX, Karl. 018 de Brumário de Luís Bonaparte. São Paulo: Boitempo, 2011.

MÉSZÁROS, István. Para Além do capital. Campinas: Unicamp, 2008.

MOTA, Ana Elizabete. Expropriações contemporâneas: hipóteses e reflexões. In:

BOSCHETTI, Ivanete. Expropriações e direitos no capitalismo. São Paulo: Cortez, 2018.

OLIVEIRA, Francisco de. Crítica à razão dualista: o ornitorrinco. São Paulo: Boitempo, 2013.

POCHMANN, Márcio. Nova classe média? O trabalho na pirâmide social brasileira. São Paulo: Boitempo, 2012.

SINGER, André. Os sentidos do lulismo: reforma gradual e pacto conservador. São Paulo: Companhia das Letras, 2012.

TROTSKY, Leon. A revolução permanente. São Paulo: Expressão Popular, 2007. 


\begin{abstract}
Carlos Roberto Marinho da Costa II Trabalhou na concepção e delineamento ou análise e interpretação dos dados; redação do artigo ou a sua revisão crítica.

Doutorando em Serviço Social- UFPE, possui graduação em Serviço Social pela Universidade Federal de Pernambuco (2008), Especialização em Gestão Ambiental pela Universidade de Pernambuco- UPE (2009), Especialização em Planejamento e Gestão de Recursos Financeiros na Política de Saúde pela FIOCRUZ/IMIP (2011) e mestrado em Serviço Social pela Universidade Federal de Pernambuco (2015, foi professor substituto da UFPE. Atualmente é docente do curso de Serviço Social do Centro Universitário UNINASSAU-Recife. Integra a diretoria do CRESS- $4^{a}$ Região, na função de tesoureiro, coordenador da comissão de inscrição e coordenação da comissão de form ação profissonal, além de Secretario Municipal de Assistência Social de Barreiros-PE.Atuou como coordenador estadual do Programa Casa das Juventudes da Secretaria de Criança e Juventude do estado de Pernambuco, como Secretário Adjunto de Assistência Social do município de Pombos-PE . Possui experiência na área de Serviço Social, com ênfase em Assistência Social e Proteção Social, fundo público e o financiamento da política de Assistência Social.
\end{abstract}

Rosa Maria Cortês Trabalhou na concepção e delineamento ou análise e interpretação dos dados; redação do artigo ou a sua revisão crítica, aprovação da versão a ser publicada.

Graduada em Serviço Social pela Universidade Federal do Rio Grande do Norte (1973). Mestre em Serviço Social pela Universidade Federal de Pernambuco (1991). Doutora em Planejamento Urbano e Regional pelo Instituto de Pesquisa e Planejamento Urbano e Regional-IPPUR/UFRJ (2006). Pós-Doutorado no Centro de Estudos e das Relações Interculturais (CEMRI), Universidade Aberta de Lisboa(UAb), Lisboa, Portugal (2018). Professora Associado da Universidade Federal de Pernambuco. Professora do Programa de Pós-Graduação de Serviço Social - Departamento de Serviço Social. Líder do Núcleo de Estudo e Pesquisa em Habitação e Saneamento Ambiental-NEPHSA. Pesquisadora do Observatório de Políticas Públicas e Práticas Socioambientais (Observatório PE), integrante da Rede Nacional do Observatório das Metrópoles. Chefe do Departamento de Serviço Social-CCSA/UFPE ( 2015-2018. Coordenadora do Programa de Pós-graduação em Serviço Social (PPGSS-UFPE).Temas de estudo e atuação: Serviço Social, questão urbana, questão habitacional, autoconstrução, saneamento ambiental, assentamentos precários, lutas sociais, práticas sociais, desigualdade e pobreza urbana, políticas públicas e sociais, cidade e território, migração. 